\title{
POLÍTICAS PÚBLICAS: ESPORTE, EDUCAÇÃO; MUDANÇAS A PARTIR DA DÉCADA DE 1990
}

\author{
Daiane Patrícia Beraldi, Centro Universitário de Maringá, Maringá, Paraná- Brasil \\ Mara Cecília Rafael, Centro Universitário de Maringá, Maringá, Paraná- Brasil \\ Halny Andressa Silva, Centro Universitário de Maringá, Maringá, Paraná- Brasil \\ Vânia de Fátima Matias Souza, Centro Universitário de Maringá, Maringá, Paraná- Brasil
}

\section{RESUMO}

O objetivo deste estudo foi analisar as mudanças das políticas públicas de esporte e lazer a partir da década de 1990, para tanto se utilizou de uma metodologia bibliográfica documental, cujos pressupostos teóricos se subsidiaram no documento Política Nacional do Esporte (2003) do Ministério do Esporte. Evidenciou-se neste estudo que esse documento aponta como principais mudanças às políticas de esporte e lazer, assim como as políticas educacionais. É importante ressaltar que os Organismos Internacionais tiveram grande participação neste processo, possibilitando a realização de diversos projetos, e interferindo no planejamento e na execução destes. Conclui-se dessa forma, que as políticas públicas de esporte e lazer a partir da década de 1990, têm incorporado conceitos de participação, descentralização, focalização, privatização e parcerias em suas ações. Desta forma a responsabilidade com o esporte e o lazer vem sendo dividida entre setor privado, sociedade civil e Estado, no qual este, gradativamente vem se desresponsabilizando em oferecer o esporte e o lazer como um direito de todo cidadão. Neste sentido, destacamos que os estudos realizados nessa área fornecem subsídios teóricos para uma reflexão sobre as políticas públicas para o esporte e lazer.

Palavras-Chave: Políticas públicas, Educação, Esporte e lazer.

\section{PUBLIC POLICIES: SPORTS, EDUCATION, CHANGES FROM THE 1990'S}

\begin{abstract}
The aim of this study was to analyze the changes in public policies of sport and leisure from the 90's, so it was used a documental bibliographic methodology, which theoretical assumptions were based on the document National Policies of Sport (2003) of the Sports Ministry. It is possible to be seen in this study that this document points to main changes to policies of sport and leisure, as well as educational policies. It is important to highlight that the International Systems had great participation in this process, making it possible to perform several projects, also interfering in the planning and the execution of them. So we conclude that the policies of sport and leisure from the 90's have embedded conceptions of participation, decentralization and partnership in their actions. Thus the responsibility with sport and leisure has been divided into private, civil society and State, and this last one has
\end{abstract}


gradually stopped taking the responsibility in offering sport and leisure as a right to all citizens. In this way, we can say that the studies done in this field provide theoretical aids for a reflection on policies for sport and leisure.

Key-Words: Public policies, Education, Sport and leisure. 


\section{INTRODUÇÃO}

A Educação Física é uma área de conhecimento que tem apresentado ao longo da história, objetivos relacionados à formação e preparação do sujeito, tanto para o exercício da cidadania, quanto para desenvolvimento de suas funções no mercado de trabalho. O que significa dizer que, essa é uma área de conhecimento que se sustenta na relação estabelecida entre o meio social e as funções educativas de cada época.

Num breve olhar para a história da área, podemos notar que de acordo com as mudanças políticas, sociais e econômicas, e as Políticas Públicas voltadas para a Educação e o Esporte sempre apresentaram relevância significativa para os Governos. Nos últimos tempos essa evidência tem sido aparente, ganhando importância na sociedade, com visibilidade na mídia e na esfera acadêmica da Educação Física, em especial, a partir da década de 90, com as chamadas "Conferências Nacionais do Esporte”, organizadas pelo Ministério dos Esportes.

Ressaltamos que as Políticas Públicas compreendem as decisões do Governo nas mais diversas áreas que influenciam na vida dos cidadãos. Trata-se dos atos ou omissões do Governo que traz benefícios ou prejuízos a sociedade. Caracteriza-se por uma conduta consistente e continuada que se constitui numa sequência de decisões. ${ }^{1}$

Essas políticas se efetivaram como mudanças significativas a partir da década de 90, uma vez que nesse período o Estado abre espaço para as $\mathrm{ONG}$ 'S, sociedade civil e instituições privadas, no sentido de dividir suas responsabilidades em relação às políticas sociais, dentre 
elas as políticas para o Esporte e Lazer. Acenamos aqui para o fato de que reflexões acerca das políticas para o Esporte devam incluir uma análise crítica da situação política e econômica de caráter neoliberal, haja vista que essa análise possibilita o compreender das relações sócioeconômicas que o Esporte enquanto fator político deve dialogar.

Lembramos que o neoliberalismo visa uma "modernização" na educação, ou seja, uma adequação do ensino a competitividade internacional, uma nova vocacionalização, formação de pessoas capazes de solucionar problemas, decidirem a melhor forma de enfrentá-los, como se fosse uma auto independência do Estado para resolver suas necessidades. O neoliberalismo parte do pressuposto de que a sociedade é capaz de vencer as crises sem que para isso seja necessária a ajuda e intervenção absoluta do Estado., ${ }^{2,3}$

Diante das considerações apontadas inicialmente, e entendendo a importância da política para a conquista de direitos sociais, surgiu-nos a seguinte indagação: Visto que as Políticas Públicas tiveram grande importância e grande contribuição a partir da década de 90 , quais as mudanças que mais marcaram esse período?

Buscando responder a essa estruturação, a pesquisa consagra-se como sendo do tipo bibliográfica descritiva. ${ }^{4}$ Para tanto, além do discurso bibliográfico utilizaremos como fonte primária para a pesquisa documentos da Política Nacional e Esporte, Ministério do Esporte 2003 e o Relatório da Força Tarefa entre Agências das Nações Unidas sobre o Esporte para o Desenvolvimento e a Paz: em Direção à Realização das Metas de Desenvolvimento do Milênio.

Conexões: revista da Faculdade de Educação Física da UNICAMP, Campinas, v. 9, n. 1, p. 109-129, jan./abr. 2011. ISSN: 1983-9030 
Tendo essa estruturação delegamos como objetivos para nosso trabalho analisar as Políticas Públicas de Esporte e Lazer a partir da década de 90 e, posteriormente, apontar as principais ideias, justificativas, linhas estratégicas e propostas que articulam as políticas de Esporte e Lazer proposto pelo Estado e pelas agências internacionais após 1990, e por fim verificar as orientações da política para o Esporte e Lazer contidos nos documentos propostos pelo MEC e pelas agências internacionais a partir de 1990.

\section{ANÁLISE DOCUMENTAL}

\section{Políticas Públicas e o papel do Estado}

A Educação Física e o campo do Esporte se inserem também no debate sobre a natureza do Estado e a influência que as políticas neoliberais têm tido ao fragilizar sua capacidade de garantir direitos públicos.

A importância atribuída à questão da Reforma da Educação no ano de 1990 deve-se especialmente as ideias neoliberais, que passou a culpar o Estado pela crise financeira, por ser ineficiente, caro e centralizador. A intenção foi de reduzir o Estado ao mínimo ${ }^{1}$, ou seja, fazer com que o Estado deixe de ter o controle absoluto de tudo, e passe a dividir as responsabilidades, com a sociedade civil e o próprio mercado. ${ }^{2}$

As políticas públicas aplicadas ao fenômeno esportivo passam por idéias do senso comum que necessitam ser questionadas e analisadas, para podermos superar alguns mitos que fazem parte de slogans de campanhas esportivas que são espalhadas por todos os lugares, e muitas

\footnotetext{
${ }^{1}$ Para Mello (2004, p.39) "O Estado Mínimo, pregado pelos neoliberais, não pode ser considerado como Estado fraco, ao contrário, só não é intervencionista quanto às regras do mercado e aos gastos públicos, mas interfere, de forma direta, para garantir que os ideais neoliberais se cumpram".

Conexões: revista da Faculdade de Educação Física da UNICAMP, Campinas, v. 9, n. 1, p. 109-129, jan./abr. 2011. ISSN: 1983-9030
} 
vezes são aceitas de forma acrítica por vários fatores da área esportiva como: o esporte educa, droga mata, esporte é vida, o esporte é para todos, o esporte é saúde, o esporte é um meio de ascensão social, e outros de natureza similares.

O objetivo da reforma do Estado, segundo documentos, é reforçar a capacidade de governabilidade do Estado por meio da "transição programada de um tipo de administração pública, burocrática, rígida e ineficiente, voltada para si própria e para o controle interno, para uma administração pública gerencial, flexível e eficiente, voltada para o atendimento da cidadania". 5

Ao incorporar teorias da administração, o Estado passou a focar a qualidade e eficiência em uma administração descentralizada. Além da privatização, o Estado tem como estratégia a publicização e a terceirização, na qual é o processo de transferir para o setor privado, serviços auxiliares ou de apoio; já publicização caracteriza-se pelo processo de transferência para o setor público não estatal dos serviços sociais que o Estado presta.

Como descreve Carrano ${ }^{6}$

A noção, trabalhada a partir da década de 90 no bojo das políticas de ajuste econômico neoliberal, de que o Estado é ineficiente e as organizações sociais - terceiro setor - são melhores executoras de políticas públicas encontra um ponto de apoio em muitas iniciativas esportivas. (p. 9)

O Neoliberalismo atinge países como o Brasil de forma perversa, e busca esvaziar o Estado de certas obrigações, deixando a população cuidar de novos setores, tais como ONGs, visando assim para uma tendência privatizante, ou seja, o que antes era público passa a ser privado.

Conexões: revista da Faculdade de Educação Física da UNICAMP, Campinas, v. 9, n. 1, p. 109-129, jan./abr. 2011. ISSN: 1983-9030 


\section{TERCEIRO SETOR}

Com a redução do Estado, o setor privado começou a ajudar nas questões sociais, por meio das inúmeras instituições que compõem o chamado terceiro setor. Ou seja, o terceiro setor é constituído por organizações sem fins lucrativos e não governamental que tem como objetivo gerar serviços de caráter público. O objetivo central deste setor é a pobreza e a exclusão social, em especial do Banco Mundial².

Os principais “personagens” do terceiro setor são: Fundações (como a fundação Bradesco), Empresas, ONGs dentre outras. São aliados muito importantes do Governo, pois assim diminui a responsabilidade dele em organizar e cuidar de suas obrigações sociais e ajudar a gerar mais empregos. Desta forma, o Estado deixa de ser o único responsável pelas políticas de cunho social, abrindo espaço para a inserção de agentes privados, como complementa Silva, $^{7}$ (p. 108): “A ação de caráter universal, por meio desta lógica, gradativamente tende a ser substituída por intervenções localizadas na caridade privada e na filantropia empresarial”.

Nesta relação entre o público, o privado e o terceiro setor é que se destacam as questões do Esporte e da Educação, esta parceria enfatiza a dimensão social do Esporte que se enlaça em uma análise crítica com a dimensão política e econômica. Um exemplo desta relação é o Programa Segundo Tempo, no qual o Ministério do Esporte conta com a parceria de várias instituições para sua execução, entre eles estão os Ministérios da Educação, da Segurança Alimentar, da Defesa, do Trabalho e da Assistência Social. Participam dele, também empresa,

\footnotetext{
2 Segundo Mello (2004, p.49) "A questão da exclusão social e da pobreza está no centro das discussões das agências internacionais, especialmente do Banco Mundial. Elas são consideradas uma ameaça ao sistema vigente e, para garantir que as bases que sustentam esta sociedade se mantenham, são elaboradas e recomendadas políticas para aliviar este quadro. É preciso enfatizar que isto não significa acabar com as contradições sociais, mas trata-se de buscar alternativas que amenizem futuros conflitos sociais".

Conexões: revista da Faculdade de Educação Física da UNICAMP, Campinas, v. 9, n. 1, p. 109-129, jan./abr. 2011. ISSN: 1983-9030
} 
clubes sociais e esportivos, ONGs, Universidades, as Forças Armadas, os Governos estaduais e municipais, o Corpo de Bombeiros e policias sindicatos e associações profissionais.

Estas relações entre o público e o privado serviram para balizar no Brasil o enquadramento de uma atividade não desenvolvida pelo Estado - Primeiro Setor e tampouco pela iniciativa privada ora representante do mercado - Segundo Setor, mas sim por uma sociedade organizada - entidades sem fins lucrativos que substituiu as ações singulares, para a prática conjunta e desinteressada do bem, que forma o Terceiro Setor. ${ }^{8}$

Assim, convencionou-se chamar de terceiro setor o segmento que engloba as entidades privadas sem fins lucrativos. Ele seria uma mistura dos dois setores econômicos clássicos da sociedade: o público, representado pelo Estado, e o privado, representado pelo empresariado em geral.

- uma nova esfera pública, não necessariamente governamental;

- constituída de iniciativas privadas em benefício do interesse comum; com grande participação de organizações não-governamentais;

- e compreendendo um conjunto de ações particulares com o foco no bemestar público.

O Quadro 1 apresenta os principais elementos definidores do conceito e das características do terceiro Setor, conforme Cardoso. ${ }^{9}$

Quadro 1 - Apresentação dos elementos definidores do conceito e das características do terceiro Setor

Conexões: revista da Faculdade de Educação Física da UNICAMP, Campinas, v. 9, n. 1, p. 109-129, jan./abr. 2011. ISSN: 1983-9030 


\begin{tabular}{ll}
\hline ELEMENTOS DEFINIDORES & \multicolumn{1}{c}{ DESCRIÇÃO } \\
\hline Foco & Bem-estar público. Interesse comum. \\
Questões Centrais & Pobreza, desigualdade e exclusão social. \\
Entidades participantes & Empresas privadas, Estado, ONG’s e \\
& sociedade civil. \\
Nível de atuação & Comunitário e de base \\
Tipos de ações & Ações de caráter público e privado, \\
& associativas e voluntárias. \\
\hline
\end{tabular}

Devido à falta de investimento no setor esportivo e a abertura ao terceiro setor para as políticas no setor social como a Educação e Esporte temos, como exemplo os projetos que são criados a partir de empresas privadas, que para se adaptarem ao modelo no qual o Governo prioriza, devem criar projetos em benefício à sociedade.

Essas empresas criam associações ou instituições que vão por meio de projetos buscarem trabalhar de forma comunitária, procurando uma melhora no desenvolvimento, a fim de promover uma sociabilização e inclusão social. Essas ONG'S por sua vez, acabam recebendo certo apoio do Governo, o que faz com que diversos clubes e empresas, acabem tornando de suas “escolinhas”, ONG’S para receber também apoio financeiro do Governo.

\section{ORIENTAÇÃO DOS ORGANISMOS INTERNACIONAIS PARA A ELABORAÇÃO DA POLÍTICA NACIONAL DO ESPORTE NO BRASIL}

Interessa-nos neste ponto, identificar as orientações feitas por organismos multilaterais, do âmbito da ONU, UNESCO, BM e FMI, que junto ao financiamento de projetos econômicos, se voltam para projetos envolvendo "o setor social, como medida de alívio e de redução da pobreza [...]". ${ }^{10}$ (p. 169). Após a Segunda Guerra Mundial o mundo precisou ser restaurado Conexões: revista da Faculdade de Educação Física da UNICAMP, Campinas, v. 9, n. 1, p. 109-129, jan./abr. 2011. ISSN: 1983-9030 
para responder ao mercado capitalista internacional. Esta restauração implicou em investimentos altíssimos, e um dos maiores responsáveis por isso foi o Banco Internacional de Reconstrução e Desenvolvimento (Bird), feita esta reconstrução o Bird passou a desenvolver planos de cunho social para os países em desenvolvimento, visto que estes eram os que mais necessitavam devido à desigualdade, e uma das áreas que foi proposto um maior investimento foi na educação.

O Banco tem assistido ao setor educacional brasileiro, na forma de cooperação técnica e financeira para o desenvolvimento da educação de base. Esta assistência foi realizada por meio de projetos de cofinanciamento desenvolvidos no âmbito do Ministério da Educação nas três últimas décadas. Durante esse período, o Banco ampliou suas funções para além da assistência técnica e financeira propriamente dita, passando a elaborar políticas para os setores a serem financiados pelos seus créditos, entre eles, a educação. ${ }^{11}$ (p.28).

Desta maneira, o Banco tem investido na Educação brasileira, como forma de cooperação e auxílio financeiro aos países em desenvolvimento na Educação de base, pois acreditam que terão retorno mais rápido em relação a esta. É importante ressaltar que o Banco só financia projetos que estejam de acordo com certas orientações feitas por ele.

Conforme estabelecido na estratégia de assistência, os países desenvolvem os seus próprios projetos com o apoio técnico e financeiro do Banco Mundial. O ciclo do projeto descreve o processo de identificação, financiamento, implementação e avaliação ao longo de toda a sua duração. Várias opções de financiamento estão disponíveis de acordo com o tipo de assistência necessária. 
Os empréstimos ou créditos para esses projetos são em seguida submetidos à aprovação dos Diretores Executivos, que constituem o órgão de decisão do Banco Mundial e representam todos os países membros. É importante notar que a execução dos projetos é administrada pelo Governo do país, que estabelece um escritório, que é a Agência Implementadora responsável por alguns aspectos da implementação, como as aquisições e a seleção de consultores. ${ }^{12}$

O Brasil participou da Conferência de Educação para Todos em Jomtien na Tailândia em março de 1990. Nesta conferência pode-se notar a participação de órgãos internacionais como UNESCO, UNICEF e Banco Mundial, o qual patrocinou a Educação e priorizou o ensino fundamental, somente nas quatro primeiras séries deste, por acreditar que esta proporcionará um retorno econômico mais rápido do que as demais. ${ }^{8}$

Essa prioridade inclui o necessário esforço dos sistemas de ensino para que todas obtenham a formação mínima para o exercício da cidadania e para o usufruto do patrimônio cultural da sociedade moderna já que estas empresas acreditam que investindo na Educação básica o indivíduo terá um suporte necessário para poder trabalhar no mercado de trabalho, gerando assim rendas não só para o País, mais também para si próprio.

Concomitante ao investimento na Educação básica o Governo tem apoiado o Terceiro Setor, na qual o primeiro setor é caracterizado pelo Estado que é responsável pelas questões sociais, o segundo setor é o privado, responsável pelas questões individuais.

Nos documentos produzidos a partir de 1990 pelo BM, observa-se que ele tem reforçado o discurso de outras agências internacionais, tomando como princípio básico, a garantia do Conexões: revista da Faculdade de Educação Física da UNICAMP, Campinas, v. 9, n. 1, p. 109-129, jan./abr. 2011. ISSN: 1983-9030 
desenvolvimento com equidade por meio da Educação, o qual proporcionaria o desenvolvimento econômico e social, dando a oportunidade aos pobres se tornarem competitivos no mercado. ${ }^{8}$

Nesta relação entre o público, o privado e o terceiro setor é que se destacam as questões do Esporte e da Educação, esta parceria enfatiza a dimensão social do Esporte que se enlaça em uma análise crítica com a dimensão política e econômica, políticas devido ao marketing que o Governo estará pregando, mostrando que se investe em Esportes, focando que este é saúde para os jovens, econômica que o terceiro setor investindo nisso, muitas vezes os benefícios que forem gerados sairá como forma do Estado.

A ONU é um órgão que tem influenciado as políticas esportivas, em julho de 2003, publicou um documento intitulado: "Relatório da Força Tarefa entre Agências das Nações Unidas sobre o Esporte para o Desenvolvimento e a Paz: em Direção à Realização das Metas de Desenvolvimento do Milênio". A elaboração deste documento inicia-se com a constituição de uma Força Tarefa entre Agências da ONU "para rever as atividades que envolvem o Esporte dentro do sistema das Nações Unidas". 13

A ONU com intuito de prestar assistência a diferentes países para que atinjam as Metas de Desenvolvimento para o Milênio (MDMs) coloca o Esporte como aquele que pode contribuir para a concretização destas metas. Este documento utiliza-se do princípio da igualdade e da participação de todos nos benefícios sociais sem, em momento algum, identificar qualquer contradição entre classes sociais, raça, religião, cultura, poder econômico, etc. Nesse sentido, o Esporte é tratado como um instrumento compensatório capaz de _ desligado da totalidade Conexões: revista da Faculdade de Educação Física da UNICAMP, Campinas, v. 9, n. 1, p. 109-129, jan./abr. 2011. ISSN: 1983-9030 
das relações sociais _ facilitar a inclusão, sobretudo, de pobres, mulheres, crianças e todos aqueles considerados à margem da sociedade. Ao tratar da relação do Esporte com o desenvolvimento humano, o documento destaca que um ponto central é o desenvolvimento sustentável, baseado nos princípios da inclusão, da equidade e da sustentabilidade, a ênfase está na importância de aumentar a oportunidade para as gerações.

Apoiado nestes princípios, o Relatório em questão trata o Esporte, também como o presidente Lula, como "uma ferramenta eficaz para a mobilização social", que tem a capacidade de exercer influência sobre a saúde, reduzindo a probabilidade de doenças, por meio da mobilização social. Além de sinalizar para o potencial econômico significativo contido no Esporte, afirmando ser este um importante setor para a geração de empregos. "É também um ambiente-chave e uma atração natural para a participação de voluntários. Além disso, a prática de Esporte apóia a preservação de um meio ambiente limpo e saudável", contando sempre com a boa vontade da sociedade civil em participar. Devemos lembrar que o voluntariado é também uma forma de reduzir custos aos projetos.

Desta forma, a Força Tarefa da ONU "recomenda fortemente" que os países membros das Nações Unidas, se engajem na implantação deste programa, chamando a atenção para as seguintes questões:

"1. O esporte deve ser bem integrado na agenda do desenvolvimento. 2. O esporte deve ser incorporado como uma ferramenta útil nos programas para o desenvolvimento e a paz. 3. As iniciativas baseadas no esporte devem ser incluídas nos programas de país das Agências das Nações Unidas, conforme, apropriado e de acordo com necessidades localmente avaliadas. 4. Programas que promovem o esporte para o desenvolvimento e a paz necessitam de mais atenção e recursos por parte dos Governos e sistema das Nações Unidas. 5. As atividades baseadas na comunicação que utilizam o esporte devem

Conexões: revista da Faculdade de Educação Física da UNICAMP, Campinas, v. 9, n. 1, p. 109-129, jan./abr. 2011. ISSN: 1983-9030 
focalizar na mobilização social e na conscientização bemdirecionados, particularmente nos níveis nacional e local. 6. Uma recomendação final da Força Tarefa é que a maneira mais eficaz de implementar os programas que usam o esporte para o desenvolvimento e a paz é através de parcerias. ${ }^{13}$ (grifo do autor)

O relatório incentiva o Esporte a ser integrado nas ações políticas, o mesmo é visto como uma atividade que pode proporcionar qualidade de vida, prevenção de doenças e integração social. O Esporte possui funções utilitárias, segundo o relatório, ter uma população saudável é ter trabalhadores saudáveis e mais produtivos, ele é também uma forma barata de medicinapreventiva, além de ter em si um grande potencial econômico.

É possível identificar um discurso semelhante entre a proposta da PNE, deste documento elaborado pela $\mathrm{ONU}$, assim como o financiamento do BM na área educacional e esportiva, tais discursos trazem nas suas propostas uma adequação às políticas neoliberais, utilizando do Esporte para compensar os desajustes sociais, para incluir os excluídos e oferecer cidadania à população, oferecer a paz e desenvolvimento humano.

É, portanto, diante de tamanha adequação às políticas neoliberais que o país tem pautado suas políticas de incentivo ao Esporte nacional e, sobretudo, ao Esporte escolar e a Educação Física escolar.

\section{POLÍTICAS ESPORTIVAS}

As Políticas Esportivas tem conquistado cada vez mais seu espaço nos dias atuais, pois, antes elas eram tratadas juntamente com a Política de Educação, ocorrendo assim uma desvalorização desta área, mais isso tem tomado outro rumo desde o Governo Lula.

Conexões: revista da Faculdade de Educação Física da UNICAMP, Campinas, v. 9, n. 1, p. 109-129, jan./abr. 2011. ISSN: 1983-9030 
Quando Lula assumiu o Governo ele fez com que o Ministério do Esporte fosse separado do da Educação, melhorando assim para ambos. Porém esta decisão não foi aceita tão facilmente, para que isto ocorresse foram realizadas duas Conferências. A primeira Conferência Nacional do Esporte foi realizada em 2004, teve o tema: Criação do Sistema Nacional de Esporte e Lazer, onde uma das propostas foi à revogação da LDB, para que a Educação Física estivesse presente em todos os níveis de ensino, inclusive para os alunos do período noturno, propôs também a valorização dos profissionais de Educação Física e da formação continuada.

De acordo com informações da Ascom/ME (21/06/2004), órgão responsável por veicular notícias referentes ao Ministério do Esporte, o presidente Lula fez um discurso durante a abertura da $1^{\text {a }}$ Conferência Nacional do Esporte, e ressaltou a importância do mesmo na formação do povo brasileiro, afirmou que "junto com a Educação, o Esporte é a forma mais barata e importante de combater os males que tomam conta da juventude brasileira, como o uso de drogas, a criminalidade e a evasão escolar." O presidente, ainda, tornou pública sua concepção sobre como o Esporte deverá orientar as políticas nacionais, esclarecendo que:

Queremos fazer do esporte em nosso país uma política tão comum como escovar os dentes. Desde a fase da disputa eleitoral, assumi o esporte como instrumento fundamental do povo e o compromisso de que era preciso criar um Ministério do Esporte no Brasil, separado do turismo que é hoje um setor gerador de grande fonte de renda. $\mathrm{O}$ papel do Ministério do Esporte hoje é o de fazer desabrochar milhares de talentos que temos no setor. ${ }^{13}$ (grifo do autor).

O documento incentiva a divulgação do Esporte cada vez mais, fazendo com que ele se torne algo tão popular quanto escovar os dentes, proporcionando desta maneira uma forma de que todos pratiquem Esporte, promovendo então um país mais igualitário, diminuindo seus problemas de criminalidade, dentre outros, e passe por meio de projetos a descobrir o talento Conexões: revista da Faculdade de Educação Física da UNICAMP, Campinas, v. 9, n. 1, p. 109-129, jan./abr. 2011. ISSN: 1983-9030 
que há em cada jovem proporcionando cada vez mais incentivo ao Esporte, e suporte ao jovem.

A segunda Conferência ocorreu em 2006, onde teve como princípio básico reformular todo o documento que havia sido feito. A partir disso foram criados diversos projetos, nos quais tinham como objetivo; democratizar o acesso ao Esporte e lazer, ou seja, torná-lo mais acessível a todos; incentivar o desenvolvimento de talentos esportivos onde que, por meio dos projetos seria mais fácil de identificar; aprimorar o desenvolvimento de atletas e para-atletas de rendimento; estimular o desenvolvimento da cadeia; promover o desenvolvimento da ciência e tecnologia e por fim fomentar a prática do Esporte como fator de identidade cultural. O PNE (Política Nacional do Esporte) tem como objetivo isso, ou seja, promover a qualidade de vida da população brasileira.

Para que essas medidas fossem adotas, foram passadas por uma série de fatores, o Governo precisou se articular com outras esferas e com a sociedade, ou seja, deixou de ter somente um foco e englobou a sociedade juntamente. Ampliou e diversificou o financiamento para o Esporte em todas as suas dimensões. O Esporte como parte integrante da cultura, em sua dimensão de lazer, atende aos interesses e necessidades sociais dos cidadãos a partir das suas manifestações lúdico-esportivas.

Enfim para essas novas medidas foram criados diversos projetos das quais se encontram: Projeto Segundo Tempo, Esporte e Lazer da Cidade, Esporte Identidade Cultural, todos com o mesmo intuito de promover um país com mais igualdade em relação ao Esporte, buscando 
beneficiar as diferentes classes sociais de uma mesma forma, ou seja, por meio da inclusão e da cidadania a todos.

A inclusão social e a cidadania são tidas como palavras chaves da atualidade, possuem como princípios reverter o quadro de injustiça, exclusão e vulnerabilidade social. Castel $^{14}$ discute que o acesso ao Esporte deve ser universalizado e não focado a apenas uma classe social e que a prática do mesmo ajuda na melhora da qualidade de vida, promovendo de forma barata o desenvolvimento da saúde na população. Porém para essas medidas serem desenvolvidas são necessários financiamentos no qual constituem uma série de fatores.

A garantia de acesso ao Esporte será um poderoso instrumento de inclusão social, considerando sua importância no desenvolvimento integral do indivíduo e na formação da cidadania, favorecendo sua inserção na sociedade e ampliando sobremaneira suas possibilidades futuras. $^{13}$ (p. 16).

- A PNE é baseada nas políticas de cunho assistencialista e compensatória;

- O conceito de cidadania deve coincidir com o de humanidade;

- Superação pela via socialista, os movimentos sociais devem ir contra a via do capitalismo.

O Esporte e o Lazer no Brasil foram planejados e estruturados pelas classes dominantes, estas classes definiam o Esporte como de alto rendimento, onde apenas alguns indivíduos seriam capazes de realizar os exercícios. Voltado para os interesses das classes dominantes, o Esporte passou por diversas variações que vai desde "Esporte para todos" até a completa submissão às leis de mercado, definidas mais recentemente com a nova lei do desporto nacional.

Conexões: revista da Faculdade de Educação Física da UNICAMP, Campinas, v. 9, n. 1, p. 109-129, jan./abr. 2011. ISSN: 1983-9030 
O Estado não deve intervir mais decisivamente na economia, ou seja, a privatização das empresas irão se encarregar deste processo. A tecnologia, por exemplo, é apenas uma parte dessa dominação global que tem sido realizado sistematicamente pelas classes dominantes, e este controle determinará o domínio desta classe sobre a sociedade.

É importante que haja uma ampliação do Esporte e que ele não seja voltado apenas para uma classe social, ou a um tipo de grupo, mas sim para toda uma sociedade. Para que isso ocorra é necessária uma atenção especial dos representantes, este trabalho sendo realizado de forma ideal é possível que ocorra mudanças significantes, lembrando que os problemas sociais não são mais apenas problemas do Estado e sim das empresas privadas e da sociedade civil.

\section{CONSIDERAÇÕES FINAIS}

Diante das evidências apontadas no presente estudo, podemos concluir que a educação e o esporte passaram por uma série de fatores que proporcionaram mudanças significativas: reforma do Estado, descentralização, neoliberalismo, reforma da educação, privatização. Estes fatores que estão determinando as políticas para o esporte e lazer, que foram o ponto de partida para nossa análise.

O diálogo com os documentos analisados possibilitou-nos entender, que a educação e o esporte tomassem outros rumos, em direção a novas perspectivas partiu-se de uma reforma do Estado, cuja conotação passou a dividir tarefas, com a própria sociedade e setores privados, fazendo com que desta forma a sociedade estivesse mais envolvida na execução das políticas, tornando assim o Estado uma forma descentralizadora de poder político e social.

Conexões: revista da Faculdade de Educação Física da UNICAMP, Campinas, v. 9, n. 1, p. 109-129, jan./abr. 2011. ISSN: 1983-9030 
Nesse contexto surge e efetiva-se o terceiro setor, responsável pelas questões sociais, por meio de inúmeras instituições que compõe este setor, no qual passam a ser aliados do Governo: ONG'S, Empresas, Fundações, que criam projetos com intuito de beneficiar a sociedade, porém em troca o Governo propõe isenção de impostos para as empresas que mantém projetos sócias. Além das propostas de parceria entre instituições privadas e terceiro setor ou o Estado e o terceiro setor ou até mesmo os três setores envolvidos em projetos sociais, em especial na área esportiva.

\section{REFERÊNCIAS}

${ }^{1}$ PERONI, V. Política educacional e papel do estado: no Brasil dos anos 1990. São Paulo: Xamã, 2003.

${ }^{2}$ LIBÂNEO, J. C. Educação escolar: políticas, estrutura e organização. São Paulo: Cortez, 2003.

${ }^{3}$ OLIVEIRA, V. M. Consenso e conflito da Educação Física brasileira. Campinas, Brasiliense, 1988. 224p.

${ }^{4}$ MARTINS JUNIOR, J. Como escrever trabalhos de conclusão de curso: instruções para planejar e montar, desenvolver, concluir, redigir e apresentar trabalhos monográficos e artigos. Petrópolis: Vozes, 2008.

${ }^{5}$ BRASIL. Câmara da Reforma do Estado. Art. Constituição: Brasil, 1995b. p.12. 
${ }^{6}$ CARRANO, P. C. R. Prefácio. In: SILVA, M. R. (Org.). Esporte, educação, estado e sociedade: as políticas públicas em foco. Chapecó: Argos, 2007. p. 7-11.

${ }^{7}$ SILVA, M. R. Esporte, educação, estado e sociedade: as políticas públicas em foco. (Org.). Chapecó: Argos, 2007.

${ }^{8}$ MELLO, M. L. M. Reflexões sobre políticas brasileiras para a Educação Básica na Década de 1990. 2004 Dissertação (mestrado) - Universidade Estadual de Maringá, Maringá, 2004.

${ }^{9}$ CARDOSO, R. Terceiro setor. Disponível em: http://web.worldbank.org/WBSITE/EXTERNAL/HOMEPORTUGUESE/EXTPAISES/EXT LACINPOR/BRAZILINPOREXTN/0,,contentMDK:21352825 menuPK:4082367 pagePK:1 41137 piPK:141127 theSitePK:3817167,00.html\#projects. Acesso em: 28 set. 2009.

${ }^{10}$ FONSECA, M. O banco mundial e a educação. Reflexões sobre o caso brasileiro. In: GENTILI, P. Pedagogia da exclusão: crítica ao neoliberalismo em educação. 7. ed. Petrópolis: Vozes, 2000.

${ }^{11}$ FONSECA, M. Banco mundial e a educação brasileira. Brasília: [1996?]. (mimeo).

${ }^{12}$ BANCO Mundial. Disponível em: http://www.bancomundial.org.br. Acesso em: 29 set. 2009.

Conexões: revista da Faculdade de Educação Física da UNICAMP, Campinas, v. 9, n. 1, p. 109-129, jan./abr. 2011. ISSN: 1983-9030 
${ }^{13}$ ORGANIZAÇÃO DAS NAÇÕES UNIDAS (ONU). Relatório da força tarefa entre Agências das Nações Unidas sobre o esporte para o desenvolvimento e a paz: em direção às metas de desenvolvimento do milênio. 2003. Disponível em: http://wwwesporte.gov.br. Acesso em: 10 set. 2009.

${ }^{14}$ CASTEL, R. et al. Desigualdade e a questão social. São Paulo: EDUC, 1997. 